\title{
Una perspectiva heterodoxa de la historia de los medicamentos. Dinámicas de inclusión-exclusión de los sueros antituberculosos Ravetllat-Pla en la España del primer tercio del siglo XX
}

\section{Sara Lugo-Márquez (*)}

\author{
(*) Instituto Tecnológico Metropolitano (Medellín-Colombia). \\ Facultad de Artes y Humanidades. Grupo de investigación CTS+i. \\ saralugo@itm.edu.co
}

Dynamis

[0211-9536] 2013; $33(1): 93-118$
Fecha de recepción: 31 de mayo de 2012

Fecha de aceptación: 21 de noviembre de 2012

SUMARIO: 1.-Introducción. 2.-Exclusión del Instituto Ravetllat-Pla de la oficialidad científica catalana y española. 3.-Un nuevo espacio de inclusión para legitimar una teoría científica heterodoxa. 4.- Reconfiguración de los medicamentos desde el «estigma social» de la tuberculosis en Brasil. 5.-Conclusiones.

RESUMEN: En 1924, momento histórico de auge de la tuberculosis en España, fue fundado el Instituto Ravetllat-Pla con el fin de producir y comercializar un suero antituberculoso fundamentado en una teoría propuesta por el veterinario Joaquim Ravetllat i Stech (1872-1923). La nueva teoría etiopatológica de la tuberculosis propuesta por Joaquim Ravetllat evidenciaba la variabilidad ontológica del bacilo de Koch proponiendo nuevas formas bacterianas que no habían sido descritas. El tisiólogo catalán Ramon Pla i Armengol (1880-1958) encontró en la teoría de Joaquim Ravetllat fundamento a los síntomas clínicos que observaba en sus pacientes por lo que continuó la investigación en alianza con el veterinario. Esta teoría científica fue considerada heterodoxa por la ciencia oficial de la época lo que condujo al establecimiento de un espacio de exclusión en el que el Instituto adoptó la identidad de heterodoxo. Como reacción a la exclusión el Instituto generó otro espacio de inclusión en el que, a través del éxito comercial de sus productos farmacéuticos, su refutada teoría científica fue legitimada y validada socialmente. En el presente artículo, se propone que la consideración de los medicamentos como productos comerciales permite evidenciar la participación activa de los distintos usuarios del suero Ravetllat-Pla en su construcción, reconceptualización y legitimación social. Además, desde las dinámicas de inclusión y exclusión, esta investigación contribuye al entendimiento de los procesos de legitimación del conocimiento desde de la heterodoxia científica.

PALABRAS CLAVE: seroterapia, tuberculosis, Instituto Ravetllat-Pla, Ramon Pla i Armengol, redes entre ciencia e industria, inclusión/exclusión.

KEY WORDS: serotherapy, tuberculosis, Ravetllat-Pla Institute, Ramon Pla i Armengol, scienceindustry networks, inclusion/exclusion. 


\section{Introducción $(*)$}

Durante la primera década del siglo XX, el veterinario de Salt (Girona) Joaquim Ravetllat i Estech (1871-1923) propuso una teoría heterodoxa sobre la variabilidad del bacilo de Koch, evidenciando una nueva forma bacteriana específica que denominó bacteria de ataque o bacteria RavetllaPla. Esta segunda nominación fue adoptada después de su asociación con el médico, originario de Alentorn (Lleida), Ramon Pla i Armengol (18801958). La bacteria Ravetllat-Pla, definida como la forma más infecciosa del bacilo tuberculoso, sirvió de fundamento científico para la fabricación del suero antituberculoso Ravetllat-Pla. Este medicamento, fabricado desde 1919 en Barcelona, era obtenido de sangre de caballos inmunizados con la nueva forma bacteriana descrita y se comercializó en dos presentaciones; la «Hemo-antitoxina Ravetllat-Pla» y el «Suero Ravetllat-Pla».

Después de que en 1882 Robert Koch describiera el bacilo que lleva su nombre emergió lo que podríamos denominar «tuberculosis de laboratorio», la cual pretendía explicar la enfermedad a partir de una única causa observable, medible y cultivable. El discurso hegemónico abandonó las corrientes ambientalistas que pretendían curar la peste blanca por medio de reformas urbanas y del mejoramiento de la calidad de vida de la población, para adoptar un discurso contagionista que acabó responsabilizando a los enfermos de «contraer» la enfermedad. La monocausalidad de la tuberculosis suscitó la construcción de un imaginario social de la identidad tuberculosa estigmatizando a las personas que padecían la enfermedad ${ }^{1}$. De forma paralela, y dado el fracaso terapéutico de la tuberculina propuesta por Koch en 1890, surgieron en el primer tercio del siglo XX múltiples propuestas, más o menos efímeras, de vacunas y sueros basadas en la monocausalidad bacteriológica $^{2}$.

$\left(^{*}\right)$ Esta investigación forma parte del proyecto HAR2009-13389-C03-01 financiado por el Ministerio de Economía y Competitividad.

1. Molero-Mesa, Jorge. La tuberculosis como enfermedad social en los estudios epidemiológicos españoles anteriores a la guerra civil. Dynamis. 1989; 9: 185-223. Molero-Mesa, Jorge; JiménezLucena, Isabel. «Otra manera de ver las cosas». Microbios, eugenesia y ambientalismo radical en el anarquismo español del siglo XX. In: Miranda, Marisa; Vallejo, Gustavo, eds. Darwinismo social y eugenesia. Derivas de Darwin: cultura y política en clave biológica. Buenos Aires: Siglo XXI; 2010, p. 143-164.

2. Molero-Mesa, Jorge. La vacunación antituberculosa. Historia 16. 1990; 15 (172): 81-88. 
En este contexto, Joaquim Ravetllat, influido por Jaime Ferran i Clua $(1851-1929)^{3}$, planteó una forma propia de entender la tuberculosis ${ }^{4}$. Su propuesta sobre la existencia de una variabilidad del bacilo de Koch, permitió dar explicación a la diversidad de síntomas tuberculosos, a la imposibilidad de desarrollar una vacuna específica y a la no visualización de bacilos de Koch en extractos claramente tuberculosos, aspectos de la enfermedad que permanecían incógnitos para la medicina de la época. La teoría de Ravetllat planteaba que el bacilo tuberculoso era un microorganismo variable con tres formas ontogénicas reversibles entre sí: la bacteria de ataque, la bacteria de transición y el bacilo de Koch ${ }^{5}$. La bacteria de ataque descrita como la forma más tóxica de las tres fue denominada, tras la asociación con Ramon Pla, «Bacteria Ravetllat-Pla» y era la que se inoculaba a los caballos para producir el suero comercializado por el Instituto del mismo nombre ${ }^{6}$. Sin embargo, las instituciones médicas oficiales catalanas y españolas rechazaron esta teoría contribuyendo a la construcción de su identidad heterodoxa. La teoría bacteriológica propuesta por Joaquim Ravetllat fue para Ramon Pla la explicación biológica de cómo se expresaban clínicamente los estados orgánicos de debilidad que presentaban las clases desfavorecidas en la época y que él veía diariamente en sus pacientes tuberculosos.

Ramon Pla siempre se interesó por la tuberculosis desde el punto de vista clínico. Participó en la fundación del Patronato de Cataluña para la lucha contra la tuberculosis y fue colaborador de la Obra Antituberculosa de la Caixa de Pensions per a la Vellesa i d'Estalvis de Catalunya i Balears.

3. Bagué i Canaleta, Narcís. Aproximació a la vida i l'obra de Joaquim Ravetllat i Estech (1872-1923). Llull. 1984; 7: 3-24.

4. Sobre la influencia de estas ideas en el proceso de institucionalización de la veterinaria de laboratorio en Cataluña: Gutiérrez García, José Manuel. El impacto del laboratorio en la renovación de la veterinaria española: el caso de Joaquim Ravetllat i Estech (1871-1923). Medicina e Historia. 2007; 4:1-15.

5. La variabilidad ontogénica que defendía Ravetllat fue lo que lo distanció de los planteamientos de Jaime Ferran, quien explicaba la variabilidad del bacilo tuberculoso desde un punto de vista evolutivo.

6. Joaquim Ravetllat y Ramon Pla hicieron pública su asociación y la copropiedad de la teoría de Ravetllat en 1919 con la publicación de su primer artículo conjunto: Ravetllat, Joaquim; Pla, Ramon. Transformación in Vitro del bacilo de Koch en bacteria tuberculógena A. Revista de Higiene y Sanidad Pecuarias. 1919; 9: 547-549. Para profundizar en esta teoría científica puede consultarse: Lugo-Márquez, Sara. Ciencia, industria e ideología desde la Cataluña del siglo XX. La heterodoxia incluyente del Instituto Ravetllat-Pla (1919-1936). Barcelona: Universidad Autónoma de Barcelona; 2011 [citado 27 Jun 2012]. Disponible en: http://hdl. handle.net/10803/79126. 
Fue médico auxiliar del Laboratorio Municipal de Barcelona y participó activamente de las actividades de la Acadèmia i Laboratori de Ciències Mèdiques de Catalunya y de su revista Annals, de la que fue director en 1919. Además, contribuyó de manera fundamental a la construcción del entramado político de Cataluña. A pesar de su actividad política, científica y comercial, Ramon Pla murió en 1958 marginado de la vida social barcelonesa e invisibilizado de la memoria histórica española ${ }^{7}$.

La asociación de Joaquim Ravetllat y Ramon Pla culminó en la creación del Instituto Ravetllat-Pla fundado oficialmente en $1924^{8}$. En 1930, se terminó la sede definitiva del Instituto, una edificación noucentista de cuatro plantas, ubicada en el barrio del Guinardó de Barcelona, en una finca con una extensión de más de 40.000 metros cuadrados, que contaba con una adecuada infraestructura para la producción farmacéutica y la investigación bacteriológica de la tuberculosis (Figura 1). Desgraciadamente, el precoz fallecimiento de Joaquim Ravetllat en 1923 le impidió ver la culminación de este proyecto, dejando como único dueño del Instituto a Ramon Pla.

El Instituto se consolidó como una empresa privada de investigación y producción industrial, aislada de las instituciones científicas catalanas. Se expandió principalmente por Latinoamérica creando una red comercial en aproximadamente veintisiete países. Tras la Guerra Civil y el exilio de Ramon Pla, el Instituto fue administrado y dirigido por su hija Nuria Pla i Monseny (1916-2011), quien logró mantener la actividad comercial del mismo hasta $1980^{9}$.

A través de análisis históricos del surgimiento de nuevas tecnologías y de las ciencias aplicadas se ha propuesto una mirada específica de la sociedad de consumo de principios del siglo XX. Siguiendo los análisis de Ruth Schwartz Cowan, quien propuso que el éxito de los productos

7. Lugo-Márquez, Sara. Enfermedad, industria e ideología en la Cataluña del siglo XX. Ramon Pla i Armengol (1880-1958), entre el olvido y la heterodoxia. Medicina e Historia. 2012; 2: 3-18.

8. Copia de la escritura de compra-venta. 14 Ene 1924. Archivo del Instituto Ravetllat-Pla-Universidad Autónoma de Barcelona (en adelante AIRP-UAB), carpeta 34.4.1.0.

9. Nuria Pla, siendo todavía estudiante de medicina, se alistó durante la Guerra Civil en la Sección Femenina de la Falange Española, lo que contribuyó a que el Estado le cediera el Instituto al acabar la contienda. Estapé Egea, Marc. L'Institut Ravetllat-Pla durant la postguerra civil espanyola. reinventant la seroteràpia. Barcelona: Universidad Autónoma de Barcelona; 2011. Según su propio testimonio, la conservación de la obra de su padre fue el motivo que le llevó a pasarse al bando franquista. Entrevista personal a Nuria Pla i Monseny. Barcelona, 25 Mar 2009. 
comerciales depende también del punto de vista del consumidor, historiadores de la ciencia y de la tecnología se han dedicado a analizar cómo los usuarios «consumen, modifican, domestican, reconfiguran y resisten a la tecnología» ${ }^{10}$. Los medicamentos entendidos como productos tecnológicos y comerciales pueden ser analizados desde esta perspectiva y evidenciar como su uso incide y transforma las teorías científicas que los sustentan. En otras palabras, la concepción de los medicamentos como productos comerciales nos permite incluir a la sociedad en su configuración como productos fundamentados en el conocimiento científico.

Generalmente cuando se habla de inclusión-exclusión se hace alusión a procesos sociales, económicos y políticos que excluyen o incluyen desde el poder hegemónico a grupos sociales marginados. Sin embargo, las dinámicas de inclusión-exclusión pueden manifestarse en todas las relaciones de cada entramado sociocultural en los cuales el conocimiento científico es parte indispensable de su configuración ${ }^{11}$. Este artículo plantea cómo la exclusión de una teoría científica de un contexto oficial determinado y la adopción de una identidad propia heterodoxa permitió al Instituto Ravetllat-Pla crear un nuevo espacio de inclusión que condujo a la legitimación de su teoría científica a través de la comercialización de sus productos antituberculosos, por tanto a que el medicamento llegara a los pacientes y estos lo validaran socialmente y lo reconceptualizaran a través de su uso ${ }^{12}$.

10. Oudshoorn, Nelly; Pinch, Trevor, eds. How users matter. The co-construction of users and technologies. Cambridge: The MIT Press; 2003.

11. Luhmann, Niklas. Inclusión-exclusión. In: Complejidad y modernidad: de la unidad a la diferencia. Madrid: Trotta; 1998, p. 167-195; Bohn, Cornelia. Inclusion and exclusion: Theories and findings. From exclusion from the community to including exclusion. In: Gestrich, Andreas; Raphael, Lutz; Uerlings, Herbert, eds. Strangers and poor people. Changing patterns of inclusion and exclusion in Europe and the Mediterranean world from Classical antiquity to the present day. Frankfurt: Peter Lang; 2009, p. 35-53.

12. La presente investigación se realizó a partir del archivo del Instituto Ravetllat-Pla. En 2008 fue trasladado desde su instalación original al campus de la Universidad Autónoma de Barcelona. En la actualidad, se encuentra en proceso de catalogación. Las secciones más utilizadas para la elaboración de este artículo fueron la correspondencia con los agentes comerciales en países latinoamericanos y las publicaciones políticas, científicas y de divulgación de Ramon Pla, así como sus memorias escritas durante el exilio. 


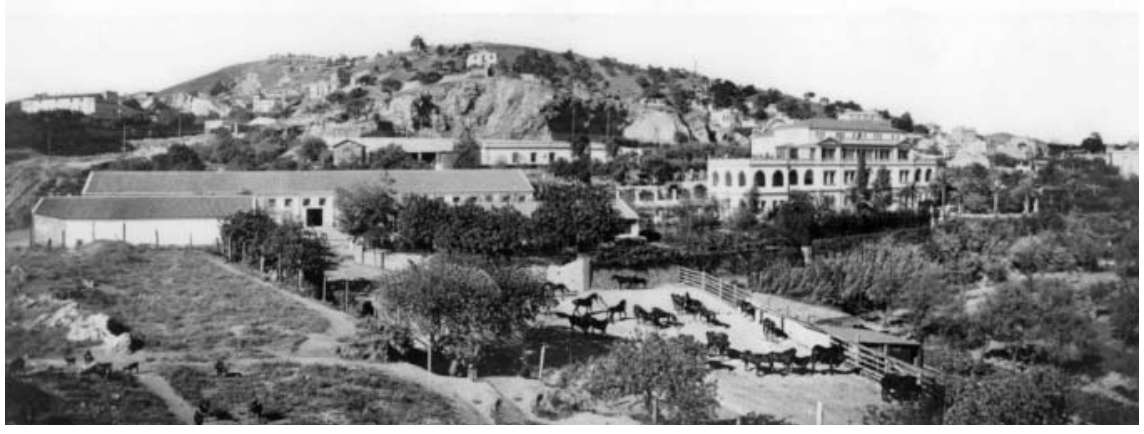

Figura 1. Vista panorámica del Instituto Ravetllat-Pla en 1935. Fuente: AIRP-UAB, sin catalogar.

\section{Exclusión del Instituto Ravetllat-Pla de la oficialidad científica ca- talana y española}

El ámbito social de exclusión construido por la oficialidad científica española y catalana en el que se consolidó el Instituto Ravetllat-Pla se valió de dos aspectos identitarios fundamentales que describiremos a continuación: el primero, la ideología izquierdista de Ramon Pla junto con la evolución de su manera especial de entender el nacionalismo catalán; y, en segundo lugar, la identidad que se asignó al Instituto, en conflicto con los intereses de las entidades médica, comerciales y farmacéuticas catalanas españolas ${ }^{13}$.

Después de terminar su bachillerato en Lleida, Ramon Pla se trasladó a Barcelona para realizar sus estudios de medicina. Fue socio del Centro Escolar Catalanista, fundado en 1886 como parte del Centre Català ${ }^{14}$ y de la Associació Escolar Republicana ${ }^{15}$. Entre 1907 y 1917 perteneció a la

13. Para profundizar en los debates de índole general sobre la bacteriología de la tuberculosis que también contribuyeron a la exclusión del Instituto Ravetllat-Pla, véase: Lugo-Márquez, n. 6, p. 49-86.

14. Esteban de Vega, Mariano; Martín, Francisco de Luis; Morales Moya, Antonio, eds. Jirones de hispanidad: España, Cuba, Puerto Rico y Filipinas en la perspectiva de dos cambios de siglo. Salamanca: Universidad de Salamanca; 2004.

15. Balcells, Albert. El projecte d'autonomia de la Mancomunitat de Catalunya del 1919 i el seu context històric. Barcelona: Parlament de Catalunya; 2010. 
Unió Catalanista. En esta primera etapa, se consideraba «un catalanista liberal y republicano, seguidor de Pi i Margall» ${ }^{16}$. Participó en la fundación de la Associació Nacionalista Catalana, adherida a la Unió Catalanista y fundada para reivindicar las expresiones del pueblo catalán ${ }^{17}$. Defendía que la constitución de Cataluña en Estado autónomo era la única forma de «recuperar la libertad de los catalanes». Estas proclamas de independencia estaban supeditadas, según Ramon Pla, a la emancipación social, una prioridad que posibilitaría la formación de catalanes capaces de manejar enteramente la libertad que la autogestión de Cataluña les otorgase ${ }^{18}$. Sin embargo, después de diez años de militancia nacionalista, Ramon Pla comenzó a sentirse inconforme con la manera de actuar de sus compañeros de partido, ya que se tornaron «insolidarios con el resto de España», promovían el «reaccionarismo dentro de Cataluña» y su estrategia incluía «la denigración sistemática del adversario político ${ }^{19}$.

Desde 1917, Ramon Pla militó en la Federación Catalana del Partido Socialista Obrero Español (FC-PSOE), siendo su presidente entre 1931 y 1932, caracterizándose más como un socialista internacionalista que nacionalista. En 1932, formó parte de la comisión creada para promover la fusión de la FC-PSOE con la Unió Socialista Catalana (USC) pero, tras el fracaso de las negociaciones y ser expulsado por «indisciplina» de la FC-PSOE ${ }^{20}$, pasó a militar en la USC. Allí, su actuación más evidente fue a través de la Associació d'Amics de la Casa del Poble de Barcelona, de la cual ya era presidente desde 1932 y con la que colaboró económicamente. Finalmente, cuando la Casa del Pueblo abrió en 1936, Ramon Pla fue nombrado presidente de su junta directiva, y ésta fue puesta a disposición de la USC y de la Unió General de Sindicats Obrers de Catalunya ${ }^{21}$. El 16 de febrero de 1936, Ramon Pla fue elegido Diputado a Cortes en la candidatura del Frente Popular y desempeñó este cargo hasta el 2 de febrero de 1939. Cinco meses después se incorporó al Partido Socialista Unificado de Cataluña (PSUC) como el resto de los militantes de la USC.

16. Pla i Armengol, Ramon. Records amb comentaris. Petit prolec a Mexic. México: 1945. ms. AIRPUAB, carpeta 40.11.0.0, p. 25.

17. Associació Nacionalista Catalana. Sesió Inaugural. Barcelona: Imprenta F. Badia; 1908, p. 9.

18. Pla i Armengol, Ramon. Tornemhi. Catalunya. 1909; 1 (1): 1-2.

19. Pla i Armengol, n. 16, p. 25.

20. El partido socialista de Barcelona expulsa a varios afiliados. La Voz (Madrid). 4 Jul 1932: 4.

21. Martínez de Sas, María Teresa; Pagès i Blanch, Pelai. Diccionari biogràfic del moviment obrer als països catalans. Barcelona: Edicions Universitat de Barcelona; 2000, p. 1081-1082. 
El recorrido político de Ramon Pla en partidos con características ideológicas diferentes fue debido a la fidelidad a sus ideas, la defensa de Cataluña desde un carácter social e internacional y su anti-conservadurismo. Las consecuencias excluyentes de su forma de entender el catalanismo y de hacer política las explicó en sus memorias escritas durante el exilio:

«m'havien dit mal espanyol quan durant la guerra defensava a Pi i Margall i els homes de la Unió Catalanista, me diuen ara mal català perquè no volia cantar "Els Segadors" dirigits pels homes de la Lliga Regionalista» ${ }^{22}$.

Al estallar la Guerra Civil española, Ramon Pla se trasladó a Francia y luego a Bélgica dónde se reunió con su familia. Por este motivo, en junio de 1937, fue expulsado del PSUC «por deserción» ${ }^{23}$, caso que fue utilizado por sus compañeros de partido para justificar las acciones tomadas contra los que abandonaron el bando republicano durante la guerra:

«El nostre proselitisme és la lluita despietada contra els anomenats emigrats, els senyorets desertors, traïdors al seu poble, a la seva pàtria, predicant en aquesta qüestió també amb l'exemple amb la expulsió del diputat Pla i Armengol» ${ }^{24}$.

En 1938, regresó a Barcelona y continuó con la administración del Instituto. Antes de que entraran las tropas franquistas en enero de 1939, Ramon Pla abandonó nuevamente la ciudad para exiliarse en París. En 1941 se instaló en Montpellier y permaneció allí hasta 1942, fecha en la que se marchó a México, en cuya capital pasó la mayor parte de su exilio. En este último país continuó escribiendo y publicando recopilaciones de sus antiguos artículos, colaboró en la Editorial Minerva, participó de las actividades del Orfeó Català y administró la Borsa del Metge Català. En

22. Pla i Armengol, n. 16, p. 24.

23. El Partido Socialista Unificado expulsa a un diputado por deserción. La Libertad (Madrid), 11 Jun 1937: 3. Esta resolución también debió de influir el paso desde Bélgica a la zona franquista, de su esposa Asumción Monseny (m. 1948) y de su hija Nuria así como la colaboración de esta última con las tropas franquistas. Entre los motivos del traslado, según Nuria Pla, estaba el miedo que les producían los frecuentes fusilamientos llevados a cabo al inicio de la guerra en un lugar muy cercano al Instituto. Entrevista a Nuria Pla, n. 9, y Estapé Egea, n. 9, p. 8.

24. Informe de Joan Comorera a la Primera Conferencia Nacional del PSUC. Treball [artículo en Internet]. 27 Jul 1937 [citado 27 junio 2012]. Disponible en: http://www.marxists.org/catala/ comorera/1937/07/25071937.htm 
1946 regresó a París donde permaneció hasta principios de 1948, año en el que se acogió a las medidas de gracia promulgadas por el régimen franquista y volvió a Barcelona.

Al margen de las particularidades políticas de Ramon Pla que, como hemos visto, le llevó a ser repudiado por todo el espectro político catalán, el Instituto se desligó de las instituciones oficiales catalanas encargadas de la lucha antituberculosa ${ }^{25}$ y del entramado farmacéutico catalán, de marcado carácter proteccionista, frente a sus planteamientos más cercanos al librecambismo ${ }^{26}$. También se distanció de las entidades reguladoras del comercio local, bajo el pretexto de que, en su Instituto, primaba la investigación y que la comercialización de sus productos era imprescindible para poder financiarla ${ }^{27}$.

Las más reconocidas instituciones oficiales sanitarias españolas también miraban con recelo las actividades del Instituto. En junio de 1925, tras la inauguración oficial del Instituto Ravetllat-Pla, el Instituto Nacional de Higiene Alfonso XIII, a instancias de la Dirección General de Sanidad, nombró una comisión para comprobar la veracidad de la teoría Ravetllat$\mathrm{Pla}^{28}$. Esta comisión de especialistas en tisiología (no en vano figuraban todos en el comité directivo de la Revista Española de Tuberculosis) concluyó que no podía comprobarse la teoría que sustentaba la fabricación del suero sometido a prueba. Ramon Pla y Justo Caballero Fernández (n. 1896), también médico del Instituto Ravetllat-Pla, presentes en los experimentos de comprobación, consideraron que el Instituto Nacional de Higiene había

25. La percepción negativa de Pla sobre la oficialidad médica catalana quedó plasmada en su libro: Un Asclepíade [Pla i Armengol, Ramon]. Nosotros (...) los sabios. México: Ediciones Minerva; 1943. Lugo-Márquez, Sara. Ciencia, industria e ideología en la Cataluña del siglo XX. El Instituto Ravetllat-Pla en Sudamérica entre 1924 y 1936. Barcelona: Universidad Autónoma de Barcelona; 2008 [citado 27 Jun 2012]. Disponible en: http://hdl.handle.net/2072/42721.

26. Pla i Armengol, Ramon. Carta a S. Pagès Murany, 10 Ago 1928. AIRP-UAB, carpeta 1.9.3.0.

27. Instituto Ravetllat-Pla. Carta a la Cámara de Comercio, industria y Navegación hispano-brasileña en España, 22 Ago 1928. AIRP-UAB, carpeta 1.9.3.0.

28. La comisión para la comprobación de la teoría Ravetllat-Pla estaba formada por: Dalmacio Garcia Izcara (1859-1927), Jefe de la sección de Veterinaria del Instituto Nacional de Higiene Alfonso XIII; Antonio Ruiz Falcó (1887-1954), Jefe de la sección de tuberculosis y futuro subdirector del mismo Instituto en 1928; Julio Blanco Sánchez (1888-1976), director del Sanatorio Lago (Tablada); Manuel Tapia Martínez (1895-1971), director del Hospital Nacional de Enfermedades Infecciosas y Francisco Rodríguez de Partearroyo (1895-1993), director del Real Sanatorio del Guadarrama y miembro de la sección de tuberculosis del Instituto. Coroleu, W. Dictamen de la Real Academia de Medicina y Cirugía de Barcelona, 26 Jun 1926, AIRP-UAB, sin catalogar. 
saboteado dichos ensayos, lo que incitó a Ramon Pla a terminar las relaciones con dicha institución ${ }^{29}$.

Se daba la circunstancia de que varios miembros del Instituto Nacional de Higiene tenían intereses en empresas privadas de sueroterapia y que el propio Director General de Sanidad, Francisco Murillo Palacios (1865-1944), era a su vez, propietario de un laboratorio que fabricaba sueros terapéuticos, circunstancia que pudo alimentar las sospechas de Ramon Pla de que las pruebas habían sido falseadas ${ }^{30}$.

No obstante, los problemas para Ramon Pla ya habían comenzado un mes antes, cuando en mayo de 1925 recibió una invitación de la Academia y Laboratorio de Ciencias Médicas de Cataluña «para que exponga y fundamente con las demostraciones pertinentes los puntos esenciales de su doctrina». También se le comunicaba que la Academia nombraría una comisión «integrada por personas competentes en el campo de la bacteriología» para supervisar las experiencias e intervenir en la comprobación de las mismas ${ }^{31}$.

Ante la solicitud de la Academia y Laboratorio de Ciencias Médicas para que la teoría Ravetllat-Pla fuera defendida experimentalmente de manera pública, Ramon Pla i Armengol, indignado por la solicitud, respondió que «la mejor manera de contestarla sería enviarle la baja de socio». En esta misma carta acusaba a esta entidad de ser una de las responsables de la invisibilización de sus trabajos en Cataluña, dado que a pesar de conocerlos desde hace años la revista Annals «no los ha mencionado». Por otra parte, argumentó que la forma de legitimación que debe solicitar una entidad científica oficial sería la publicación de artículo en las páginas de su revista: "para demostrar que no son las murmuraciones, las envidias y las difamaciones lo que despierta su curiosidad, no debería pedirme nada

29. Instituto Ravetllat-Pla. Carta a Juan Martín (Almacén de especialidades farmacéuticas nacionales y extranjeras), 29 Jul 1929. AIRP-UAB, carpeta 1.13.2.0.

30. Rodríguez Ocaña, Esteban. La intervención de la Fundación Rockefeller en la creación de la Sanidad contemporánea en España. Revista Española de Salud Pública. 2000; 74: 27-34. Varios médicos del Instituto Nacional de Higiene estaban vinculados al Instituto de Inmunoterapia (THIFT) y el Instituto de Biología y Sueroterapia (IBYS) desde su creación en 1919, como era el caso de Ruiz Falcó. Puig Raposo, Nuria. La nacionalización de la industria farmacéutica en España: el caso de las empresas alemanas, 1914-1970. Madrid: Fundación Empresa Pública; 2001.

31. Notificación de la Academia y Laboratorio de Ciencias Médicas de Cataluña a Ramon Pla, 15 Abr 1925. AIRP-UAB, sin catalogar. 
más que partir de un hecho científico en ella [la revista Annals] comunicado en relación con nuestra teoría» ${ }^{32}$.

Posteriormente, el 13 de julio de 1926, a petición del Colegio de Médicos de Barcelona y sin que Ramon Pla estuviese enterado a pesar de ser colegiado de número, la Real Academia de Medicina y Cirugía de Barcelona emitió un dictamen sobre la teoría Ravetllat- $\mathrm{Pla}^{33}$. Este dictamen se basaba en tres investigaciones independientes que habían refutado sus teorías. La primera fue la realizada en el Laboratorio Municipal de Barcelona por el médico Pedro Domingo i Sanjuán (1896-1979), el farmacéutico Enrique Perxas Rico y el veterinario José Vidal Munnè (1896-1958). La segunda, la del comandante médico de Sanidad militar José Valdés y Lambea (18881969) publicada en la revista madrileña Los progresos de la Clinica ${ }^{34}$ y la tercera, los trabajos que se realizaron en el Instituto Nacional de Higiene de Alfonso XIII, antes comentados. El dictamen de la Real Academia, también citaba la experiencia bacteriológica de dos de sus miembros: Antonio Salvat Navarro (1883-1977) y Pedro González Juan (1886-1955), quienes según aclaraban «no han emprendido trabajos destinados expresamente a comprobar la tesis del doctor Pla i Armengol (...) [pero, concluyen que] jamás hallaron bacterias parecidas a las descritas como de ataque» 35 .

Debido a la «coincidencia» de todos estos investigadores, la Real Academia dictaminó:

«Debe reconocer esta Real Academia que los hechos descritos por los señores Ravetllat y Pla i Armengol, no se hallan hasta ahora en dicho caso de aceptación amplia por las principales escuelas bacteriológicas del mundo; y sí negadas, por el contrario, por investigadores bien acreditados cuyos informes, provistos de explicaciones cumplidas sobre las labores realizadas, merecen toda clase de respeto científico. De todo lo cual se deduce que la teoría de los señores Ravetllat y Pla i Armengol acerca de la etiología y de la patogenia de la tuberculosis, carece de base científica objetiva comprobada y quizás tampoco comprobable» ${ }^{36}$.

32. Pla i Armengol, Ramon. Carta a Jesús Maria Bellido i Golferichs, 5 May 1925. AIRP-UAB, sin catalogar.

33. Felip Proubasta i Masferrer como presidente del Colegio de Médicos de Barcelona. Carta a Ramon Pla, 22 Jul 1926. AlRP-UAB, sin catalogar.

34. Valdés Lambea, José. Estudios experimentales sobre la nueva bacteriología de la tuberculosis según Ravetllat-Pla. Los Progresos de la Clínica. 1925; 13 (165): 367-374.

35. Notificación, n. 31.

36. Coroleu, n. 28. 
En su respuesta, Pla denunció los pocos hechos experimentales que presentó la Real Academia para refutar su teoría y arremetió contra la misma por su parcialidad y trato desigual que suponía la petición del dictamen al Colegio de Médicos, ya que a ningún otro investigador se le exigía este requisito ${ }^{37}$. Los médicos oficialistas catalanes apuntaban razones no científicas para desacreditar la teoría de Ravetllat-Pla como que ésta no había sido aceptada «por las principales escuelas bacteriológicas del mundo» ${ }^{38}$. Oficialmente desde 1901, la aceptación de las teorías científicas por las escuelas bacteriológicas reconocidas a nivel mundial era definitiva para la legitimación de la estrategia antituberculosa en España, convirtiendo al bacilo en un arma de propaganda nacional que justificaba la llamada «guerra al esputo» y la modificación de las «costumbres populares» a las que culpabilizaban de difundir la enfermedad ${ }^{39}$. Por lo tanto, un germen variable, como el que proponían Joaquim Ravetllat y Ramon Pla, problematizaba la bacteriología oficial de la tuberculosis proponiendo el abandono de las categorías conceptuales establecidas por el pensamiento dominante, aunque desde la misma posición reduccionista y sin desmarcarse de las ideas de especificidad etiológica.

Los ataques que sufrió la teoría Ravetllat-Pla en 1926 por parte de la Real Academia de Medicina y Cirugía de Barcelona, pueden interpretarse como una estrategia de la misma para permanecer en la oficialidad de la ciencia hegemónica europea. Esto sólo podía conseguirlo rechazando las teorías que atentaran contra «la integridad del bacilo de Koch», como muy bien lo expresaron en el dictamen:

«Declara esta Real Academia que admite como tesis cierta, que desde el descubrimiento del bacilo tuberculógeno por Robert Koch hasta nuestros días, el ascenso científico general ha sancionado algunas modificaciones del tipo patrón; pero, en ningún caso, ha quebrantado la unidad específica de dicho germen ${ }^{40}$.

Desde este momento la teoría Ravetllat-Pla fue considerada «heterodoxa» por la comunidad médica y el propio Ramon Pla fue tildado de

37. Pla i Armengol, Ramon. Carta a la Real Academia de Medicina y Cirugía de Barcelona, 5 Ago 1926. AIRP-UAB, sin catalogar.

38. Coroleu, n. 28.

39. Molero Mesa, n. 1.

40. Coroleu, n. 28. 
mercantilista por la explotación comercial que hacía de sus productos sin estar sustentados en postulados aceptados internacionalmente. En este misma época, y posiblemente suscitada por la controversia descrita, la exportación de los sueros se orientó hacia Latinoamérica y se comenzó la creación de la red científico-comercial del Instituto. Partiendo del conocimiento empírico, de la cura de los enfermos por el suero que fabricaba, Ramon Pla hablaba «en heterodoxo (...) para sostener opiniones diferentes a las que sostienen los mantenedores de la ciencia hecha, de la ciencia que podríamos llamar oficial» ${ }^{41}$.

Sin embargo, en 1932, en una investigación realizada en The Rockefeller Institute for Medical Research de Nueva York, sobre las formas rápidas no-ácido resistentes del bacilo de Koch, fue citada la teoría Ravetllat-Pla como un antecedente más, de una corriente científica en desarrollo sobre la bacteriología de la tuberculosis, nombrando incluso técnicas de coloración que se utilizaban en el Instituto ${ }^{42}$. Las ideas Ravetllat-Pla fueron citadas hasta 1964 en otras revistas científicas como Journal of General Microbiolology ${ }^{43}$. Actualmente la polémica persiste, las formas bacterianas que se asocian al bacilo de Koch todavía son una incógnita, y están siendo redefinidas desde un punto de vista genético ${ }^{44}$. Algunos investigadores proponen que se retome la posibilidad de incluir las formas pleomórficas de las bacterias como parte del ciclo de vida bacteriano ${ }^{45}$.

\section{Un nuevo espacio de inclusión para legitimar una teoría científica heterodoxa}

El Instituto Ravetllat-Pla se constituyó en un ámbito de exclusión generado desde la ciencia oficial y las instancias políticas, comerciales, civiles, militares y farmacéuticas españolas. Para continuar su labor científica y

41. Pla i Armengol, Ramon. Estudios sobre tuberculosis. Bacteriología, patogenia clínica. México: Unión Tipográfica Hispano-Americana; 1944.

42. Miller, Franklin R. The induced development of non-acid-fast forms of bacillus tuberculosis and other mycobacteria. Journal Experimental Medicine. 1932; 56: 411-424.

43. Csillag, Anna. The mycococcus form of mycobacteria. Journal of General Microbiolology. 1964; 34: 341-352.

44. Stewart, Graham R; Robertson, Brian D; Young Douglas B. Tuberculosis: a problem with persistence. Nature Reviews Microbiology. 2003; 1: 97-105.

45. Zhang, Ying. Persistent and dormant tubercle bacilli and latent tuberculosis. Frontiers in Bioscience. 2004; 9: 1136-1156. 
la comercialización de sus productos creó un nuevo espacio de inclusión que se configuró en una red transnacional a través de veintiocho países, principalmente latinoamericanos, toda una estrategia comercial para la legitimación de su teoría científica. El análisis de dicha estrategia pone de manifiesto tres procesos fundamentales y complementarios. El primero, la teoría científica misma que ya en su planteamiento incluía los llamados estados pre-tuberculosos en la definición de tuberculosis y por lo tanto en los dispositivos sociales para afrontar la enfermedad. El segundo, la estrategia comercial que incluía a médicos locales en la verificación de la eficacia de los medicamentos. Y por último, los nuevos espacios de comunicación científica que el Instituto Ravetllat-Pla editó y distribuyó a nivel mundial, indispensables para incluir la heterodoxia científica en las discusiones oficiales sobre la tuberculosis.

Comercialmente, la estrategia para legitimar su teoría científica partía de la legalización de los sueros Ravetllat-Pla como productos comerciales en cada contexto local ${ }^{46}$. La reglamentación de los medicamentos permitiría controlar la preparación e industrialización de las especialidades farmacéuticas y los productos opoterápicos españoles, por medio de los registros obligatorios y desde el pago obligatorio de impuestos ${ }^{47}$. Este tipo de regulación perseguiría, junto con otros procesos de burocratización, la legitimación de los cada vez más intervencionistas Estados-nación emergentes de la época. Sin embargo, este proceso no fue implementado como tal. Recientemente, se ha descrito cierto momento de incertidumbre en el que no existía una regulación definida por parte de los Estados europeos para el acceso a los productos farmacéuticos ${ }^{48}$. Fue precisamente este

46. La legalización comercial de los productos Ravetllat-Pla se realizó en más países de los que finalmente se vendió, incluyendo España. El único país en el que se tiene documentada la negación de autorización para la venta fue en los Estados Unidos de América. Negativa que se encuentra documentada en el AIRP-UAB.

47. Las patentes fueron un importante mecanismo de control estatal de los medicamentos en la primera mitad del siglo XX. Específicamente, el suero Ravetllat-Pla cumplía con los requerimientos solicitados por la ley de propiedad industrial y contaba con marca registrada, pero no tenemos registro de que en la primera década del siglo hayan patentado los medicamentos. Para profundizar en los análisis de las patentes como forma de regulación véase Romero de Pablos, Ana. Regulation and the circulation of knowledge: Penicillin patents in Spain. Dynamis. 2011; 31 (2): 363-383.

48. Gaudillière, Jean Paul; Hess, Volker. Ways of regulating: therapeutic agents between plants, shops and consulting rooms, Preprint 363. Berlin: Max-Planck Institute for the History of Science; 2008. 
distanciamiento entre control científico y legislativo lo que permitió que Ramon Pla legitimara la teoría Ravetllat-Pla a través de la comercialización de sus sueros.

Así mismo, asumir una identidad de heterodoxo fue determinante para la estrategia de legitimación de la teoría Ravetllat-Pla. El Instituto se apropió de la retórica de la heterodoxia que defendía la validez de cualquier método en la búsqueda del conocimiento científico siempre que, abierto a las críticas y a la discusión de los expertos, se demostrara su validez terapéutica. De esta forma, construyó nuevos espacios de comunicación y de acción científica que no necesitaban estar avalados por la ciencia oficial, pero que necesitaban legitimación social que permitiera el consumo de los sueros antituberculosos Ravetllat-Pla:

«Se nos abren con esto nuevos caminos y amplios horizontes para el estudio de una enfermedad que, siguiendo la doctrina ortodoxa basada en la concepción bacteriológica clásica, permanece desde hace muchos años sin avanzar en el mejor conocimiento de su patogenia y de sus manifestaciones clínicas, lo mismo que en la eficacia de su terapéutica y su profilaxis. Precisa pues ser heterodoxos y orientarnos por caminos nuevos» ${ }^{49}$.

Partiendo de la teoría bacteriológica de Joaquim Ravetllat, Ramon Pla se convirtió en un detractor de las teorías que defendían la vigorización orgánica para luchar contra la enfermedad, apoyando la responsabilidad única de los bacilos. En su opinión, la infección tuberculosa afectaba a la totalidad de la población, justificando las diferencias en su manifestación mediante el concepto de «latencia». Ramon Pla no hablaba, pues, de «causas predisponentes» sino que incluía en el cuadro clínico tuberculoso a los, en su opinión, mal llamados «pretuberculosos», quienes estaban siendo excluidos del sistema médico porque no presentaban una sintomatología clínica clásica y por la ausencia del bacilo de Koch en sus organismos ${ }^{50}$. Esta concepción posibilitaba su deseo de que toda la población fuera considerada tuberculosa, lo que legitimaría una medicalización masiva y el acceso de todas las personas a medidas encaminadas a lograr condiciones higiénicas de vida óptimas. Para Ramon Pla, los supuestos «estados pretuberculosos»

49. Ravetllat i Estech, Joaquim; Pla i Armengol, Ramon. La bacteria de la tuberculosis. Publicaciones del Instituto Ravetllat-Pla. 1924; 2: 59.

50. Pla i Armengol, Ramon. Contribución al estudio de la herencia de la tuberculosis. Barcelona: Publicaciones del Instituto Ravetllat-Pla; 1926. 
se corresponderían en realidad a una tuberculosis declarada, que podía ser combatida de manera muy temprana por los sueros Ravetllat-Pla. Esta explicación etiológica incluyente de la tuberculosis le permitió formular sus dos premisas fundamentales: «todos somos tuberculosos»y «todos debemos ser tratados como tales» ${ }^{51}$.

Desde el punto de vista comercial, el primer paso para configurar la red transnacional fue el nombramiento en cada país de agentes comerciales, la mayoría de ellos catalanes sin formación médica. El agente comercial, después de haber legalizado la importación de los productos, se encargaban de su comercialización y publicitación. El contacto inicial de los agentes con la comunidad era a través de la distribución de muestras gratis a los médicos locales. En estas visitas, los agentes entregaban tarjetas postales para que los médicos solicitaran directamente al Instituto muestras o literatura sobre sus productos. Las muestras gratuitas daban a conocer el producto y hacían posible la experimentación y la comprobación de la eficacia de los medicamentos en cada contexto local. Los agentes comerciales también promovían la experimentación con los sueros Ravetllat-Pla y enviaban los resultados obtenidos para ser divulgados en las publicaciones del Instituto.

Como ya mencionamos, la admisión de la «heterodoxia» como identidad y retórica, permitió a Ramon Pla escapar al control social y construir nuevos espacios de comunicación científica, como fueron las publicaciones del Instituto, la correspondencia con agentes comerciales y la publicidad del Instituto. La estrategia de difusión implementada por Ramon Pla permitió construir relaciones horizontales con miles de médicos a nivel mundial y retroalimentar sus teorías científicas. El Instituto Ravetllat-Pla contó con tres tipos de publicaciones, todas ellas editadas y financiadas de forma autónoma. La primera, la colección Notas clinicas sobre tuberculosis, publicada entre 1923 y 1946, consistía en una recopilación de ensayos clínicos con los medicamentos Ravetllat-Pla realizados por médicos que no pertenecían a la plantilla del Instituto y que avalaban la teoría. La segunda, se denominó Publicaciones del Instituto Ravetllat-Pla y se publicó entre 1922 hasta 1940, con el fin de divulgar los nuevos resultados obtenidos en las investigaciones del Instituto. Finalmente, La Clínica. Revista Mensual Hispano-Americana de Ciencias Médicas, que muy pronto se convirtió en

51. Pla i Armengol, Ramon. Diagnòstic precós de la tuberculosis pulmonar. Barcelona: Imprenta de F Badia; 1910. 
la publicación más importante del Instituto. Sirvió de plataforma para el tránsito de conocimiento científico entre España y Latinoamérica desde 1924 hasta 1936, de modo que no sólo propició la comunicación entre científicos latinoamericanos y españoles sino también entre científicos de diferentes países latinoamericanos. Dicha publicación se configuró como un nuevo espacio para la heterodoxia que permitía a científicos excluidos de la oficialidad expresar sus teorías médicas constituyéndose a su alrededor una embrionaria comunidad médica heterodoxa ${ }^{52}$. Ésta, además, daba cabida a personas con unas características ideológicas particulares, como por ejemplo su director, Enric Mias Codina (1885-1956), que era médico gineco-obstreta y miembro de la logia masónica Themis de Barcelona; o Miguel José Alcrudo Solórzano (1884-1936), pediatra y colaborador de la revista, que era masón además de anarquista ${ }^{53}$.

Los agentes comerciales visitaban cada vez más cantidad de médicos locales y a partir de 1928, el Instituto solicitó un formulario por cada visita que contenía la dirección del médico, razón de la visita y opinión sobre los productos. Dichos formularios eran guardados y archivados sistemáticamente y se recuperaban de ellos los comentarios alusivos a la efectiva acción terapéutica de los sueros Ravetllat-Pla para ser utilizados como avisos publicitarios. La publicidad del Instituto se caracterizaba por renunciar al «gran público» y dirigirse exclusivamente a círculos científicos. $\mathrm{Su}$ fortaleza radicaba en el hecho de estar confeccionada por los mismos médicos locales que legitimaban su uso en cada contexto. Así mismo, los médicos eran incentivados para realizar estudios más completos, con un mayor número de pacientes, para ser publicados en la revista del Instituto. La publicidad del Instituto Ravetllat-Pla se convirtió así en otro medio de comunicación científica que complementaba la investigación.

Ramon Pla promovió el diagnóstico precoz de la tuberculosis y la demostración clínica de la eficacia de los sueros Ravetllat-Pla entre médicos de ciertas especialidades. Ello posibilitó configurar un grupo de consumidores integrado por los profesionales más receptivos a la campaña antituberculosa

52. En las páginas de la revista La Clínica pueden evidenciarse artículos con aproximaciones teóricas que los mismos autores denominan heterodoxas, la asociación entre diabetes y enfermedades infecciosas, la propuesta de una nueva forma de tuberculosis cuyo síntoma era las fiebres en mujeres embarazadas y las nuevas perspectivas sobre la teoría inmunológica son tres ejemplos de estas. Lugo-Márquez, n. 6, p. 135-136.

53. Lugo-Márquez, n. 6, capítulo 3.2. 
planteada por el Instituto. Los pediatras eran unos de esos profesionales gracias al gran éxito cosechado por los sueros en el tratamiento de la tuberculosis infantil. También los cirujanos fueron un colectivo prioritario, ya que combinaban los tratamientos quirúrgicos con la hemo-antitoxina para el periodo de recuperación de sus pacientes. Estos grupos defendieron y publicitaron la eficacia de los productos Ravetllat-Pla de manera determinante ${ }^{54}$. Por otra parte, para promover el diagnóstico precoz de la tuberculosis, Pla dirigió su atención hacia los médicos rurales y generales, quienes buscaban una medicina más preventiva, obteniendo de manera exitosa su apoyo para la comercialización y receta de los sueros RavetllatPla. Sin embargo, muchos de estos, apoyados por sus experiencias negativas, principalmente por las reacciones anafilácticas, también se convirtieron en detractores de las concepciones Ravetllat-Pla.

La estrategia de expansión de los mercados locales se moldeó de acuerdo a los contextos sociopolíticos, geográficos y científicos locales, e incluyó tanto los dispositivos sociales para enfrentar la enfermedad de cada localidad como las representaciones sociales de la misma. Los conceptos de enfermedad, la consideración social de los enfermos, el uso de los medicamentos y los procesos comerciales de cada ciudad contribuyeron de manera determinante en la configuración del Instituto Ravetllat-Pla.

\section{Reconfiguración de los medicamentos desde el «estigma social» de la tuberculosis en Brasil}

A pesar de ser una de las principales causas de muerte a nivel mundial, la tuberculosis no fue una prioridad para el Estado brasilero hasta entrada la segunda década del siglo XX ${ }^{55}$. Después de las aportaciones de Koch a la etiología bacteriana de la tuberculosis, los científicos brasileros, como los del resto del mundo, se esperanzaron falsamente en implementar una terapéutica específica para la peste blanca, propusieron la tuberculina como un método de diagnóstico útil para la tuberculosis bovina y comenzaron a

\footnotetext{
54. Lugo-Márquez, n. 6, capítulo 3.2 y anexo 3.

55. Benchimol, Jaime. A instituição da microbiología e a história da saúde pública no Brasil. Ciência \& Saúde Coletiva. 2000; 5: 265-292.
} 
realizar experiencias en pacientes tuberculosos ${ }^{56}$. Abierto el debate sobre la importancia de la enfermedad en Rio de Janeiro, algunos médicos de elite con visión filantrópica y un discurso científico progresista, fundaron en 1900 la Liga Brasilera Contra a Tuberculose. Hasta este momento no se contaba con una terapéutica eficaz contra esta enfermedad, por lo tanto las acciones de la Liga se centraron en la difusión de propaganda médica sobre el carácter curable de la enfermedad y los métodos para evitar su contagio, la creación de dispensarios donde pudieran ser tratados los tuberculosos, el mejoramiento de las condiciones de vivienda, trabajo y alimentación de la clase trabajadora y el aislamiento de los tuberculosos por parte de los hospitales ${ }^{57}$.

Hasta los años veinte, en los que entraron al mercado brasilero los sueros Ravetllat-Pla, la Liga Brasilera Contra a Tuberculose era de las pocas instituciones preocupadas por el problema sanitario que presentaba para Brasil la tuberculosis ${ }^{58}$. Uno de sus contribuciones fue la inauguración del Dispensario Azevedo Lima en 1907. A partir de este momento la fundación de diversos dispensarios y sanatorios en zonas climáticas del país propicias para la cura de la tuberculosis fue un proceso significativo en la lucha contra la enfermedad ${ }^{59}$. Los medicamentos antituberculosos utilizados por los médicos brasileños para combatir la peste blanca eran en su mayoría expectorantes, antisépticos, astringentes, anestésicos locales o reconstituyentes, que buscaban un tratamiento sintomatológico y no incorporaban en sus bases científicas la utilización de la reacción inmunológica producida por el bacilo tuberculoso ${ }^{60}$. Los medicamentos Ravetllat-Pla también fueron

56. Nascimento, Dilene. Fundaçao Ataulpho de Paiva. Liga Brasileira Contra a Tuberculose. Um século de luta. Rio de Janeiro: FAPERJ y Quadratim Editoras; 2002. Nascimento, Dilene. As pestes do século XX. Tuberculose e Aids no Brasil, uma história comparada. Rio de Janeiro: Editora Fiocruz; 2005.

57. Nascimento, 2002, n. 5.

58. En la primera década del siglo XX ya había naufragado una estrategia profiláctica muy ambiciosa contra la tuberculosis (inmersa una reforma sanitaria general) propuesta por Oswaldo Cruz en 1907, mientras era Director General de Salud Pública (1903-1909), que implicaba una gran inversión por parte del Estado, ya que buscaba la creación de una red de sanatorios, colonias sanitarias, dispensarios, hoteles, casas de pensión, además de la regulación del comercio de alimentos, la desinfección de lugares públicos, entre otras reformas urbanas y legislativas. Benchimol, Jaime. Manguinhos do sonho à vida. A ciência na belle époque. Rio de Janeiro: Casa de Oswaldo Cruz - Fiocruz; 1990.

59. Bertolli Filho, Claudio. História social da tuberculose e do tuberculoso: 1900-1950. Rio de Janeiro: Editora Fiocruz; 2001, p. 129.

60. Nascimento, 2005, n. 5. 
distribuidos a través de los sanatorios antituberculosos. En 1929, por ejemplo, el Sanatorio Cavalcanti, en Bello Horizonte, incluyó los productos en su recetario ${ }^{61}$. También existen evidencias de su uso en 1928 en el Sanatorio de Palmyra ${ }^{62}$ y en el Sanatorio Paqueta ${ }^{63}$. En 1930, en el Sanatorio militar de Itatiaya, se recetaban los medicamentosy se realizaban investigaciones sobre la bacteria Ravetllat-Pla ${ }^{64}$.

El Estado brasilero adoptó una visión más intervencionista con la creación del Departamento Nacional de Salud Pública, cuya dirección fue encargada a Carlos Chagas (1879-1934). Esto se tradujo en la formación en 1923 de la Inspección de Profilaxis de la Tuberculosis. Su director, José Plácido Barbosa da Silva (1871-1938), direccionó la lucha antituberculosa en cuatro sentidos: las campañas higiénicas educativas, la notificación y registro de los tuberculosos, su aislamiento y la desinfección de hogares, hospitales, fábricas, escuelas. Además, tenía como parte de sus objetivos el abastecimiento de sueros y vacunas para la población brasilera ${ }^{65}$. En 1927, la Inspección contaba con cinco dispensarios, que funcionaban articulados con la Liga y que también realizaban acciones terapéuticas ${ }^{66}$.

El estigma social que existía en Brasil sobre la «enfermedad del pecho» 67 o tuberculosis era determinante no sólo para el quehacer de los médicos brasileros sino para la construcción del concepto de esta enfermedad en Brasil. Según Claudio Bertolli, «la muerte física prometida por la enfermedad tenía como etapa anterior la exclusión social» ${ }^{68}$. Cuando se estableció la medicina de laboratorio, el concepto social de la tuberculosis en Brasil también cambió significativamente. Ya no se consideraría la tuberculosis desde el punto de vista romántico, como la enfermedad de las «almas sensi-

\footnotetext{
61. Juliá Serrat, Buenaventura. Carta al IRP, 1 Ago 1929. AIRP-UAB, carpeta 24.4.3.0.

62. Juliá Serrat, Buenaventura. Carta al IRP, 31 Mar 1928. AIRP-UAB, carpeta 24.2.1.0.

63. Juliá Serrat, Buenaventura. Carta al IRP, 10 May 1928. AIRP-UAB, carpeta 24.2.1.0.

64. Juliá Serrat, Buenaventura. Carta al IRP, 29 Ene 1930. AIRP-UAB, carpeta 24.6.1.0.

65. Nascimento, 2005, n. 5.

66. Nascimento, 2005, n. 5.

67. Bertolli Filho, Claudio. Antropologia da doença e do doente: percepções e estratégias de vida dos tuberculosos. História, Ciências, Saúde-Manguinhos. 2000; 6 (3): 493-522.

68. Bertolli Filho, n. 59 .
} 
bles» e intelectuales ${ }^{69}$, sino que pasó a ser la enfermedad de los moralmente degenerados, «víctimas de la miseria» ${ }^{70}$.

En los primeros años del siglo XX, desde el discurso médico brasilero se contribuyó a la divulgación del nuevo concepto de los tuberculosos, por medio de folletos, carteles y almanaques. Se enseñaba a la población las características físicas y morales de los tísicos y las maneras de evitar con ellos el contacto directo. Estas representaciones desataron la exclusión social de las personas enfermas quienes, por recomendación de los tisiólogos de la época, eran recluidas en sanatorios cuando la disponibilidad de camas y su situación económica lo permitían. El miedo al aislamiento social debido a la estigmatización de la enfermedad y a las corrientes contagionistas llevó a que las personas se resistieran a ser consideradas tuberculosas. Por tanto, si en los países europeos, los «pretuberculosos» quedaban fuera del sistema profiláctico oficial por motivos doctrinales, en Brasil, además, los propios pacientes favorecían, por su miedo a la enfermedad, esta exclusión. Por el contrario, las propuestas de Ramon Pla constituían un ámbito de inclusión y además convertía en indispensables a estos «nuevos» pacientes en el discurso profiláctico del Instituto Ravetllat-Pla. En 1930, se puso de manifiesto la necesidad de que la venta de los productos del Instituto estuviera acompañada por la difusión de la teoría científica Ravetllat-Pla completa, incluyendo su concepción de «todos somos tuberculosos». Según la apreciación del agente comercial Buenaventura Juliá Serra, los estados «pretuberculosos» en Brasil no eran considerados como tales, y por lo tanto no eran atendidos por el sistema médico brasilero:

«Hay que tener en consideración que aquí reina el pánico a la tuberculosis, se llama débil o flaco al que ya es tuberculoso y tuberculoso al que ya está completamente tísico, de modo que siempre la medicación resulta casi nula, por ser empleada fuera de tiempo ${ }^{71}$.

El estigma social que suponía ser etiquetado de tuberculoso hacía que los médicos buscaran formas alternativas de diagnosticar y tratar a los pacientes para que estos siguieran sus consejos. Esto condujo a un cambio

69. Pôrto, Ângela. A vida inteira que podia ter sido e que não foi: trajetória de um poeta tísico. História, Ciências, Saúde-Manguinhos. 2000; 6 (3): 523-550.

70. Soares, Pedro Paulo. A dama branca e suas faces: a representação iconográfica da tuberculose. História, Ciências, Saúde-Manguinhos. 1994; 1 (1): 127-134.

71. Juliá Serrat, Buenaventura. Carta al IRP, 3 Jun 1930. AIRP-UAB, carpeta 24.6.1.0 
en el lenguaje médico de la época: se evitaban palabras como tuberculoso o tísico y se sustituyeron por eufemismos tales como «débiles de pulmón» ${ }^{72}$. Los productos Ravetllat-Pla, al declararse antituberculosos y llevar en su etiqueta las palabras «tuberculosis» y virus de la «tuberculosis», no podían ser recetados porque los pacientes no querían ser tratados como tales:

«Aquí que la palabra tuberculoso parece un estigma y que al que se le emplea la tal palabra es un muerto, los médicos al tuberculoso lo llaman flaco o débil y se entretienen con remedios como reconstituyentes que no hacen más que dar tiempo a que se vuelvan tísicos y entonces incurables. En este estado los llaman tuberculosos. (...) Hay médicos aquí que recetarían más los productos del Instituto, pero dicen que la etiqueta de la Hemo les priva de hacerlo, pues, en ella está la palabra tuberculosis y que el enfermo se asusta al ver que lo tratan como tal, alegando que él no está tuberculoso» ${ }^{73}$.

El agente comercial pidió entonces al Instituto que se omitiera la palabra tuberculosis de los prospectos de los medicamentos. A lo que respondieron que hacer esto iría contra de sus principios porque según las teorías que promulgaban era indispensable que se asumiera que todos eran tuberculosos y fueran tratados como tales. Esta contradicción ideológica no fue suficiente para mantener los productos tal y como eran. Finalmente, el Instituto dijo a su agente comercial que haría el cambio de la palabra «tuberculosis» por «infección fímica» $\mathrm{y}$ «bacteria de la tuberculosis» por «bacteria de la T» (Figura 2).

La complejización y encriptación del lenguaje utilizado en los sueros Ravetllat-Pla suponía para el agente comercial una buena estrategia para combatir el estigma de la tuberculosis en su país, es decir, para de una $u$ otra forma, «engañar» a los pacientes, vistos por él como pertenecientes al «vulgo ignorante», y lograr su objetivo final que era la venta y consumo de los sueros Ravetllat-Pla: «Las modificaciones que ustedes me indican las encuentro muy acertadas, pues la palabra fímico y bacteria de la T no son conocidas del vulgo como las que en la actualidad están figurando» ${ }^{74}$. Sin embargo, este cambio no se llevó a cabo y en junio de 1932, Juliá Serrat volvió a retomar el tema pidiendo que se cambiara las etiquetas de los productos. El Instituto volvió a responder negativamente y propuso al agente

\footnotetext{
72. Bertolli Filho, n. 59, p. 129.

73. Juliá Serrat, Buenaventura. Carta al IRP, 22 Sep 1930. AIRP-UAB, carpeta 24.6.1.0.

74. Juliá Serrat, Buenaventura. Carta al IRP, 2 Dic 1930. AIRP-UAB, carpeta 24.6.1.0.
} 


\section{HEMO-ANTITOXINA}

\section{RAVETLLAT-PLA}

Plasma hemático de cabollos in. munizados con formas cocb́ceas de eMycobocterium tuberculosiss mezclado a partes iguales con glicerino. TONICO GENERAL

Registrado en la Dirección General

de Sanidad con el núm. 284 en 25 noviembre 1924

INSTITUTO RAVETLLAT-PLA

Avenida V. de Montserrat, 114 BARCELONA (Espoño)

Representanies en Ecuador CENTRO FAEMACEUTICO

MARZO \& C. : S. A.

L. de Goroicoo, 909.919 GUAYAQUIt
HEMO-ANTITOXINA RAVETLLAT-PLA

Plasma hemático de cavalos imu. nixados contro as mais activas toxinas do virus fímico, misturado com glicerina em partes iguais.

\section{5 c.c.}

Registado no Direç̧ồ Geral de Savide de Espanha com o n." 284 em 25 Norembro 1924.

INSTITUTO RAVETLLAT-PLA Avenida $\mathrm{V}$. de Montserrat, 114 BARCEIONA (Espanho)

Figura 2. Etiquetas de la Hemo-antitoxina Ravetllat-Pla antes y después de su reconfiguración. Fuente: AIRP-UAB, sin catalogar.

comercial otra estrategia, que los médicos dijeran a sus pacientes que este medicamento no era solamente para la tuberculosis sino que también curaba estados pretuberculosos, entre los que Ramon Pla incluía una inmensa cantidad de síntomas, muchos de ellos relacionados con el pauperismo y las malas condiciones sociales en las que vivían las clases pobres:

«Les diremos sinceramente que si nos resistimos a suprimir la palabra tuberculosis de etiquetas y prospectos es porque juzgamos que se hace un gran beneficio a los tuberculosos informándoles que lo son. Creemos haberle expuesto nuestro modo de pensar (...) a pesar de que pueda originarnos alguna pérdida material (...) Creemos que a aquellos médicos timoratos que aún les espanta la palabra tuberculosis y no se les puede convencer de que digan a 
los enfermos que lo son pero que si se cuidan se pueden curar, se les puede aconsejar que digan al enfermo que el producto no sólo es para combatir la tuberculosis, sino para prevenirla, (...) y que si se fijan en las etiquetas verán que en las indicaciones se consigna que además de servir para tratar la tuberculosis es especialmente eficaz en los llamados estados pretuberculosos y en las formas atípicas de la infancia (linfatismo, escrofulismo, bronquitis de repetición, inapetencia, enflaquecimiento, anemia, astenias diversas, fiebres vagas, etc.) y de los adolescentes (palpitaciones, cefalalgias, neurastenias, debilidad, perdidas de peso, inapetencia, astenias digestivas, estreñimiento, clorosis, dismenorreas, bronquitis frecuentes, etc.) ${ }^{75}$.

El agente comercial siguió insistiendo sobre este particular en informes de ventas y correspondencias que enviaba al Instituto y logró persuadir al Instituto de la importancia de este cambio. En abril de 1932 el instituto le escribió:

«hemos pensado serenamente sobre ella [la dificultad de que apareciese la palabra tuberculosis en las etiquetas de los productos] y hemos llegado a la conclusión de que quizás somos demasiado quijotes al querer sostener en beneficio de los enfermos la palabra tuberculosis en las etiquetas y prospectos en contra de la opinión de muchos médicos y en perjuicio de nuestros intereses y de los de usted. Nos hemos hecho estas reflexiones y estamos en principio dispuestos a cambiar la redacción de las etiquetas y prospectos, seguramente sustituyendo la palabra tuberculosis por fimis o infección fímica» ${ }^{76}$.

No fue hasta 1933 que el Instituto aceptó finalmente «velar», como decía Juliá Serrat, la enfermedad tuberculosa de la configuración de los medicamentos. Esto fue llevado a cabo no sólo para los sueros Ravetllat-Pla comercializados en Brasil sino de manera más general, en la descripción pública del medicamento que se realizaba en la etiqueta a nivel mundial:

«nos es grato poner en su conocimiento que hemos definitivamente resuelto modificar las etiquetas y prospectos de nuestros productos, no solo para el Brasil, sino también para España y para algún otro país. La modificación consistirá en sustituir en las etiquetas donde dice: Plasma hemático total..., bacteria de tuberculosis por virus fímico. Suprimir completamente todo el

\footnotetext{
75. Médico director del IRP. Carta a Buenaventura Juliá Serrat, 29 Jun 1932. AIRP-UAB, carpeta 24.6.1.0.

76. Médico director del IRP. Carta a Buenaventura Juliá Serrat, 22 Abr 1932. AIRP-UAB, carpeta 24.6.1.0.
} 
lado izquierdo de la etiqueta o sea todo el párrafo de indicaciones, y modificar el prospecto sustituyendo la palabra tuberculosis por infección fímica ${ }^{77}$.

Finalmente en 1933, se replantearon la descripción de los sueros RavetllatPla y se abandonó la «lucha quijotesca» de considerar como tuberculosa a toda la población. La ruptura provocada por el estallido de la Guerra Civil española en 1936 posibilitó la aparición de nuevos contextos de legitimación y el diseño de diferentes estrategias de comercialización y difusión científica en el Instituto Ravetllat-Pla, así como una nueva reconceptualización de los medicamentos que escapan al análisis de este artículo $^{78}$.

\section{Conclusiones}

Como se ha puesto de manifiesto en este trabajo, al entender los medicamentos como productos tecnológicos que se comercializan y consumen podemos describir la participación de los enfermos en los procesos de construcción y legitimación científica a través de sus resistencias y reacciones frente al consumo de estos productos farmacéuticos. Las reacciones contestarías de los enfermos se traducen en un proceso de modificación y reconceptualización de los medicamentos mismos, los cuales se configuran incluyendo los imaginarios sociales de salud y enfermedad. Así mismo, esta perspectiva nos permite plantear otra mirada de los imaginarios, procesos, dispositivos y prácticas sociales que se construyen frente a los conceptos de salud y enfermedad.

Un caso de estudio como el del Instituto Ravetllat-Pla, establecido en un ámbito de exclusión, nos permite no sólo dilucidar los procesos de la legitimación y validación social de la ciencia heterodoxa, sino también de la ortodoxa, la cual se constituye en procesos de legitimación que no son generalmente cuestionados por ser oficiales. La estrategia de legitimación que el Instituto propuso, nos muestra la importancia del análisis de los espacios de comunicación en el proceso de construcción, divulgación y apropiación del conocimiento científico. En este caso particular, la publicación de una

77. Médico director del IRP. Carta a Buenaventura Juliá Serrat, 6 May 1933. AIRP-UAB, carpeta 25.6.1.0.

78. Estapé Egea, n. 9. Este autor desarrolla en la actualidad su tesis doctoral sobre el proceso de reconceptualización de los medicamentos Ravetllat-Pla en los años de la postguerra española. 
revista propia como La Clínica permitió a Ramon Pla incluirse en la construcción de la ciencia (moviéndose en el ámbito heterodoxia-ortodoxia).

Ramon Pla i Armengol murió excluido de la vida pública el 6 de febrero de 1958 en su casa-laboratorio de Barcelona. No obstante, valiéndose de la retórica de la heterodoxia y del distanciamiento entre ciencia y Estado para la regulación de los medicamentos, consiguió legitimar y validar socialmente su teoría científica a partir de la construcción de una red científico-comercial y de la comercialización del suero Ravetllat-Pla. Este nuevo espacio de inclusión generado por el Instituto excluyó a las instituciones científicas oficiales de la legitimación de sus teorías, produciendo una pérdida en la reciprocidad con el sistema establecido y la invisibilización histórica de Ramon Pla i Armengol. Dicha invisibilización se evidencia por la falta de reconocimiento histórico de sus acciones científicas y políticas pese a su participación en sucesos determinantes en la historia de Cataluña y de España. 


\section{A heterodox perspective on the history of drugs. Inclusion- exclusion dynamics of the Ravetllat-Pla anti-tuberculosis serum in the first third of the 20th century}

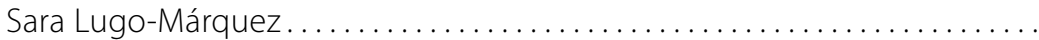

1.- Introduction. 2.-Exclusion of the Ravetllat-Pla Institute from the official Catalan and Spanish scientific contexts. 3.-A new space for inclusion to legitimize a heterodox scientific theory. 4.-Reconfiguration of medicines from the tuberculosis «social stigma» in Brazil. 5.-Conclusions.

ABSTRACT: In 1924, a historically peak time for tuberculosis in Spain, the Ravetllat-Pla Institute was established with the aim of producing and commercializing an anti-tuberculosis serum and researching the variability of the bacteria implicated in this infection. This bacterial form, proposed by Joaquim Ravetllat in the first decade of the 20th century, led to the formulation of a new etiological-pathologic theory of tuberculosis, which upheld the drugs produced by the Institute and was considered heterodox by the official science of the time. The Catalan medical and political network established a space of exclusion leading to the marginalization of the Institute, which, by strengthening its heterodox identity, generated another space of inclusion. In this space, its refuted scientific theory could be socially legitimated and validated through the commercial success of its pharmaceutical products. In this paper, we suggest that the consideration of medicines as commercial products illustrates the active participation of the different users of the Ravetllat-Pla serum in its social construction, re-conceptualization and legitimization. Moreover, from the theoretical framework of inclusion-exclusion dynamics, this research contributes to understanding the processes of knowledge legitimatization by scientific heterodoxy. 